\title{
Morton's Neuroma; Surgical Exploration Is an Option in Symptomatic Patients with Normal Investigation
}

\author{
Syed Mohsin Ali' ${ }^{1}$, Mujtaba Ahmed Siddiqi² \\ ${ }^{1}$ King Abdullah Medical City Hospital, Manama, Bahrain \\ ${ }^{2}$ National Guard Hospital, Al-Hassa, Saudi Arabia \\ Email: smali2233@yahoo.com
}

How to cite this paper: Ali, S.M. and Siddiqi, M.A. (2018) Morton's Neuroma; Surgical Exploration Is an Option in Symptomatic Patients with Normal Investigation. Open Journal of Orthopedics, 8, 413-417.

https://doi.org/10.4236/ojo.2018.811042

Received: February 6, 2018

Accepted: October 29, 2018

Published: November 1, 2018

Copyright $\odot 2018$ by authors and Scientific Research Publishing Inc. This work is licensed under the Creative Commons Attribution International License (CC BY 4.0).

http://creativecommons.org/licenses/by/4.0/

\begin{abstract}
Morton neuroma is well described problem to metatarsophalangeal Joint (MTPJ) Etiology of Morton's Neuroma which has wide range of problems from trauma, and nerve hypertrophy etc. Clinical evaluation is very important for diagnosis and sometimes investigations like ultrasound or MRI scan are helpful for conformation of diagnosis. Management varies from orthotics, shoe modification, injections or surgical excision. We are reporting a case which showed importance of surgical exploration when investigation is normal and difficulty in making diagnosis clinically.
\end{abstract}

\section{Keywords}

Neuroma, MRI, Orthotics, Exploration, Hypertrophy

\section{Introduction}

Reporting a case of unusual presentation of Morton's Neuroma, where all the investigations, MRI, Ultrasound, X-ray, CT scan, and CT SPECT were normal; Morton's Neuroma has wide range of problems from trauma, and nerve hypertrophy etc. Management of this condition is from use of orthotics, shoes modification, injections, physiotherapy and surgical excision.

We would like to elaborate the importance of clinical examination and surgical exploration in such case when treating surgeon is not clear about the diagnosis and investigations are normal.

\section{Case Report}

We are reporting a case of unusual presentation of Morton's Neuroma in a 55 
year female. This patient was referred from another hospital with chronic pain at in fore foot mainly at the 3 - 4 MT heads. She reported difficulty in walking and pain while wearing shoe. Previously she was treated with different regimens of steroids and local anesthesia injection, orthotics and physiotherapy. But there was no relief in her symptoms. She has a history of Type 2 diabetes, no history of any trauma or injury.

On examination, she presented with a normal looking foot. Pain while standing on tip toes and flexing of the fore-foot. There were no signs of a palpable mass in the web spaces or metatarsalgia. Only positive finding was pain in $3^{\text {rd }}$ web space on metatarsal head compression; equivocal Mulder's click. In last few months she underwent extensive investigation like MRI, Ultrasound, X-ray, CT scan, CT SPECT of the foot and all were reported norma (Figures 1-3).

After discussion and reviewing of investigation we agreed to proceed with surgical exploration of $3^{\text {rd }}$ Web space. Under general anesthesia surgical exploration was done through dorsal approach.

Intra-operatively intra-digital nerve was very thick, hyperemic and hypertrophic. This portion was excised and sent for histopathology. The results showed that excised portion of nerve have features of Morton's Neuroma (Figures 4-6).

Post-operative there was complete relief of pain and now patient have no restriction of any shoe wear after 6 months of surgery.

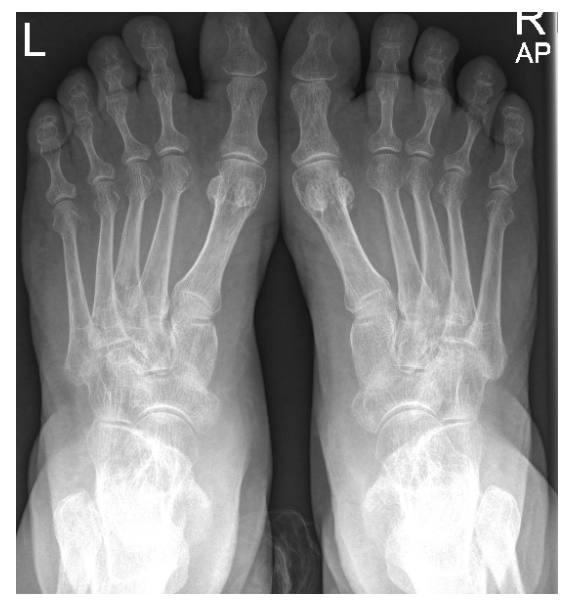

Figure 1. X-ray AP view both foot.

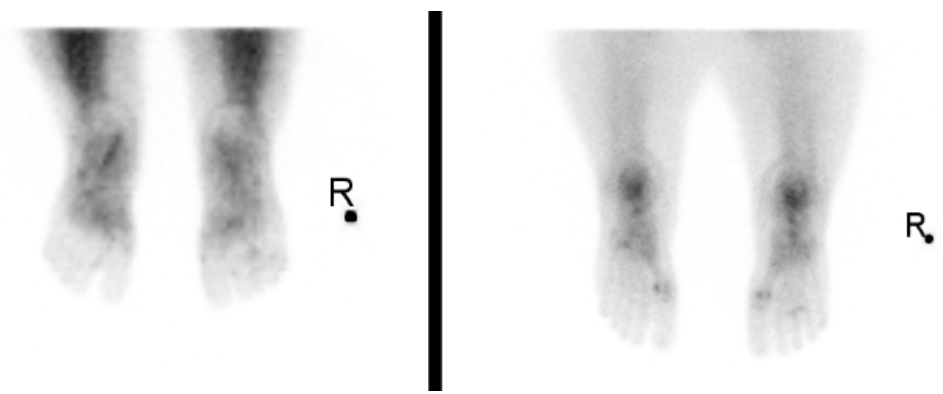

Figure 2. Bone scan both foot. 


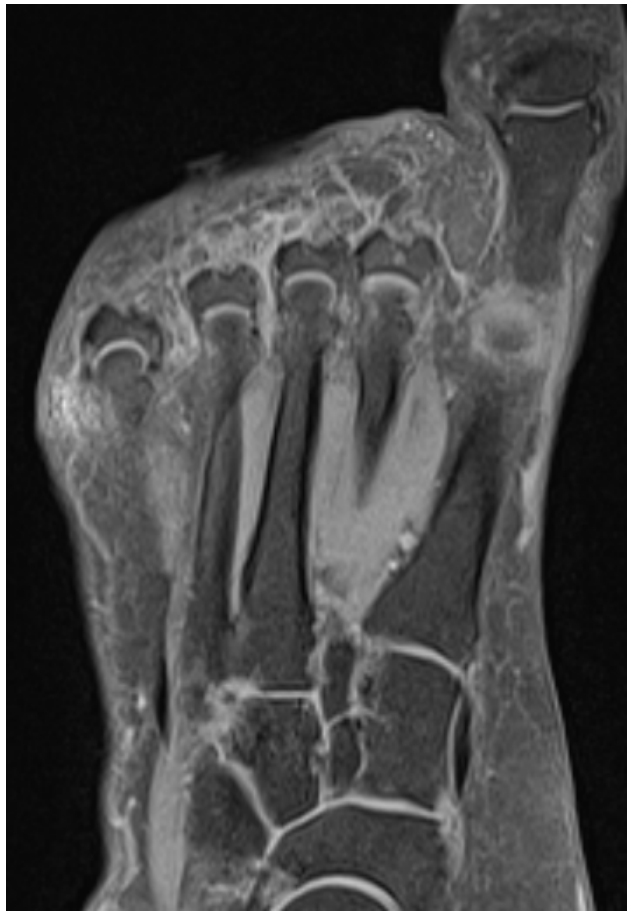

Figure 3. MRI scan right foot.

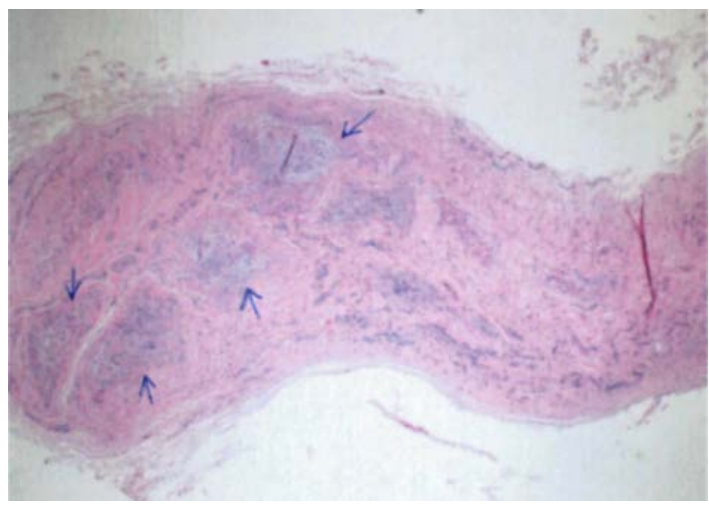

Figure 4. Nerve (Right foot/third web space) excisional biopsy: Morton's Neuroma. Ill-defined fibrosis around vaguely thickened, distorted nerve fascicles [H \& E stain].

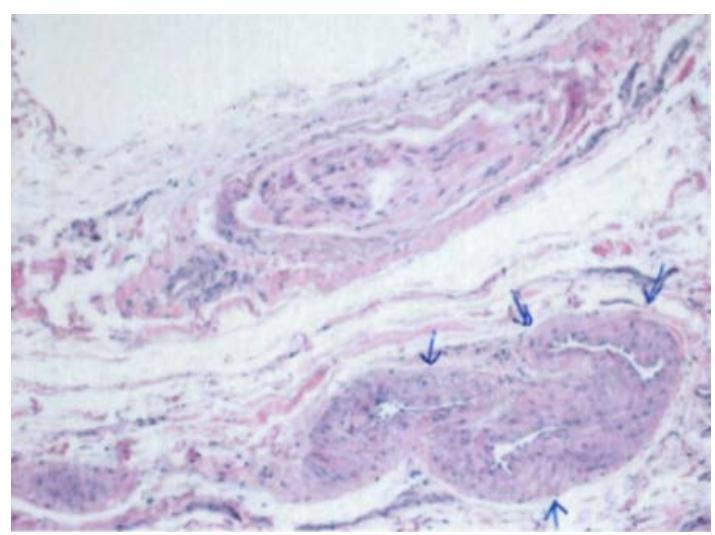

Figure 5. Nerve (Right foot/third web space) excisional biopsy: Morton's Neuroma. Prominent arterial thickening of the Vasa Vasorum [H \& E stain]. 


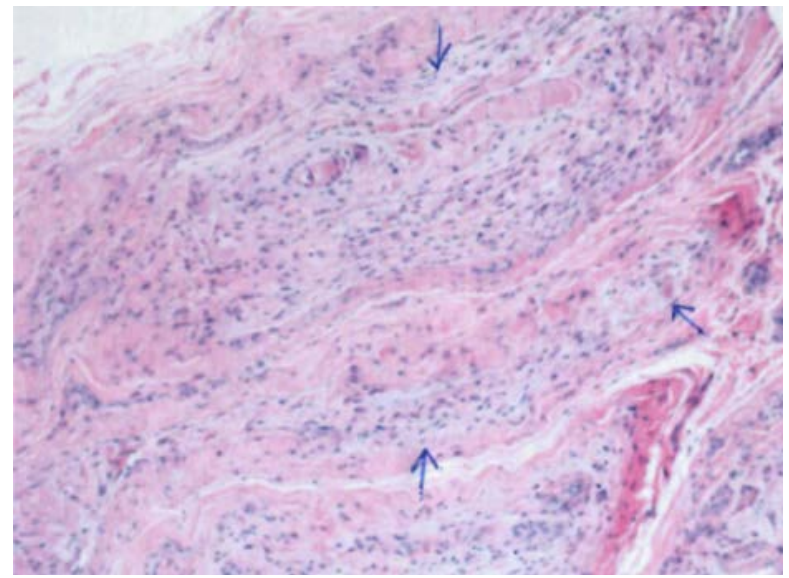

Figure 6. Nerve (Right foot /third web space) excisional biopsy: Morton's Neuroma. Variable degree of axonal myoxid degeneration [H \& E stain].

\section{Discussion}

Morton in 1876 first described and related the problem to fourth metatarsophalangeal Joint (MTPJ) and suspected a neuroma or some type of hypertrophy of digital nerve [1]. Etiology of Morton's Neuroma may be due to chronic pressure on the digital nerve beneath the transverse intra-metatarsal ligament which can lead to transverse perinerve endoneural fibroma [2].

Different diagnosis can be synovitis, osteoarthritis of metatarsal phalangeal joint or Keratosis. Some cases in literature have been reported with repeated trauma, degenerative MIPJ, inflammatory arthritis or wearing narrowed shoes [3].

Clinical evaluation like Mulder's click is the most important tool in diagnosing Morton's neuroma [4]. Imaging like ultra-sound scan has a high sensitivity rate of $95 \%$ but is non-specific with a rate of $65 \%$ only. MRI use for detecting and diagnosing intra digital neuroma remains open to debate [3] [4] [5] [6] [7].

Treatment of Morton's Neuroma began with non-surgical methods such as modification of shoes anti-inflammatory medication steroid injection with or without local anesthesia [5] [6] [7] [8].

Surgical excision should consider when non-surgical treatment is ineffective. Different methods have been described in literature for Morton's Neuroma surgical treatment. Available surgical options are from excision of digital nerve, Intermetatarsal ligament resection and MT shortening osteotomy [6].

Approach can be dorsal or plantar. No significant difference was found between two approaches [7]. Many surgeons use dorsal approach for primary case and planter approach for revision cases.

In this case all investigations were reported as normal and non-surgical methods like shoe modification, injections, physiotherapy and orthotics did not help her to improve her symptoms. With patient consent we proceed with surgical exploration and sample was sent for histology which confirms the diagnosis or Morton's Neuroma. 


\section{Conclusions}

Surgical exploration is a choice of treatment when there is no clear evidence of pathology and symptoms are not improving with conservative method. Treating surgeon should keep in mind in such case that radiological investigation can be normal as in this case.

Although planter approach has shown lesser rate of re-occurrence but still most commonly dorsal approach is used for primary cases.

\section{Conflicts of Interest}

The authors declare no conflicts of interest regarding the publication of this paper.

\section{References}

[1] Morton, T.G. (1876) A Peculiar and Painful Affection of Fourth Metatarsophalangeal Articulation. The American Journal of the Medical Sciences, 77, 37-45.

[2] Giannini, S., et al. (2004) Intradigital Neuroma: Clinical Examination and Histological Results in 63 Cases Treated with Excision. Foot and Ankle International, 25, 79-84. https://doi.org/10.1177/107110070402500208

[3] Read, J.W., Noakes, J.B., Kerr, D., Crichton, K.J., Slater, H.K. and Bonar, F. (1999) Morton's Metatarsalgia: Sonographic Findings and Correlated Histopathology. Foot Ankle and International, 20, 153-161. https://doi.org/10.1177/107110079902000303

[4] Mulder, J.D. (1951) The Causative Mechanism in Morton's Metatarsalgia. JBJS, 33B, 94-95. https://doi.org/10.1302/0301-620X.33B1.94

[5] Espinosa, N., Seybold, J.D., Jankauskas, L. and Erschbamer, M. (2011) Alcohol Sclerosing Therapy Is Not Effective Treatment for Interdigital Neuroma. Foot and Ankle International, 32, 576-580. https://doi.org/10.3113/FAI.2011.0576

[6] Park, E.H., Kim, Y.S., Lee, H.J. and Koh, Y.G. (2013) Metatasal Shortening Osteotomy for Decompression of Morton's Neuroma. Foot and Ankle International, 34, 1654-1660. https://doi.org/10.1177/1071100713499905

[7] Akermark, C., Crone, H., Saartok, T. and Zuber, Z. (2008) Plantar versus Dorsal Incision in the Treatment of Primary Intermetatarsal Morto's Neuroma. Foot and Ankle International, 29, 136-141. https://doi.org/10.3113/FAI.2008.0136

[8] Markovic, M., Crichton, K., Read, J.W., Lam, P. and Slater, H.K. (2008) Effectiveness of Ultrasound-Guided Corticosteroid Injection in the Treatment of Morton's Neuroma. Foot and Ankle International, 29, 483-487. https://doi.org/10.3113/FAI.2008.0483 